\title{
CIDADES MASSIFICADAS, CIDADES DA DITADURA
}

\section{Massed Cities, Cities Dictatorship}

\section{Michel Goulart da Silva}

História - UFSC

michelgsilva@yahoo.com.br

\section{Resumo}

Discute-se neste artigo o uso do conceito de "cidades da ditadura" para designar as cidades médias brasileiras que passaram por intensos processos de transformação ao longo da ditadura civil e militar iniciada em 1964. Para tanto, trabalha-se com a ideia de "cidade massificada", proposta por José Luis Romero, entendendo que as cidades da ditadura são uma etapa de aprofundamento na massificação pela qual vinham passando essas cidades. Nesse sentido, neste artigo analisam-se as políticas empreendidas pela ditadura brasileira no sentido de promover profundas transformações urbanas, na organização espacial das cidades e as implicações culturais desse processo.

\section{Palavras-chave}

Cidade; Ditadura; Cultura.

\section{Abstract}

This paper discusses the use of the term "cities of the dictatorship" to designate the average Brazilian cities that have undergone intense transformation processes over the civil and military dictatorship that began in 1964. To this end, we work with the idea of "mass city" proposed by José Luis Romero, understanding that cities are one step from dictatorship to deepen the massification by which came through these cities. Accordingly, this article analyzes the policies undertaken by the Brazilian dictatorship to promote deep urban transformations in the spatial organization of cities and the cultural implications of this process.

\section{Keywords}

City; Dictatorship; Culture.

Muitas das cidades brasileiras contemporâneas passaram por um intenso processo de transformações urbanas nas últimas décadas do século $X X$. Nessas 
cidades, cujo tecido urbano está marcado por diferentes temporalidades, foram produzidos discursos acerca dessas transformações, do seu passado, do seu presente e mesmo do seu futuro, além de ter sido um espaço praticado por diferentes sujeitos, desde os citadinos até os planejadores urbanos. Neste artigo o interesse volta-se para as chamadas cidades médias, no Brasil, que passaram por transformações produzidas de forma intencional pelos gestores públicos da ditadura civil-militar, nas décadas de 1960 e principalmente de 1970. Entende-se que muitas dessas cidades médias podem também ser chamadas de cidade da ditadura, na medida em que nesse período há nessas cidades numerosos elementos comuns no que se refere às transformações urbanas, como a intensa intervenção estatal nos espaços públicos, por meio do planejamento, e a produção de representações acerca das cidades.

Discute-se neste artigo as práticas e representações relacionadas à construção dessas cidades da ditadura, partindo da bibliografia disponível nas Ciências Humanas, cotejando esses estudos com algumas das transformações ocorridas no espaço urbano brasileiro nas últimas décadas do século XX. Na primeira parte do artigo discute-se 0 processo de construção da cidade massificada, fazendo uso da tipologia desenvolvida por José Luis Romero, cujo eixo passa pela reflexão acerca dos processos de transformação das cidades latino-americanas, iniciado por volta de 1930. Na segunda parte, discutem-se as características do processo de transformação das cidades médias na década de 1970, apontando diferentes elementos desse processo a partir da análise de documentos produzidos pelo poder público. Propõe-se neste artigo que a cidade da ditadura, tomando como exemplo a experiência brasileira, pode ser entendida como um desdobramento da cidade massificada, ou seja, as transformações produzidas no final do século nessas cidades seriam parte do processo de modernização iniciado na sociedade latino-americana na década de 1930.

Embora seja possível traçar essa relação, não parte-se do entendimento de que ambas sejam fases que se sucedem ou de camadas que se sobrepõem, mas de tecidos urbanos que se imbricam e se reelaboram, sem que o passado seja apagado ou mesmo destruído. Segundo Bernard Lepetit (2001, p. 138), os elementos que compõem a cidade surgem "de uma pluralidade de tempos descompassados cujas modalidades de combinação geram mudanças a cada instante". No espaço da cidade convergem, "num mesmo tempo os fragmentos de espaço e os hábitos vindos de diversos momentos do passado" (LEPETIT, 2001, p. 141). Essa pluralidade de tempos sobrepostos e intercaldos permite afirmar que a cidade "nunca é absolutamente sincrônica: o tecido urbano, o comportamento dos citadinos, as políticas de 
planificação urbanística, econômica ou social desenvolvem-se segundo cronologias diferentes" (LEPETIT, 2001, p. 145).

Essa forma de ler as cidades possibilita encarar esses espaços transformados pelas ações do Estado não como invenções discursivas do autoritarismo ou produções espaciais e socioeconômicas criadas naquele contexto, mas como reinvenções das cidades produzidas em períodos anteriores. Essas cidades são produto de longas e profundas lutas econômicas, políticas e simbólicas. Nesse sentido, partindo de Adrián Gorelik (2005, p. 111-114), pode-se entender a cidade como construção cultural, na medida em que se constitui em um espaço vivido, construído e representado pelos sujeitos que nela atuam, moldando-a e produzindo discursos acerca dela.

\section{Da cidade burguesa à cidade massificada}

Quando se analisa as cidades médias que sofreram profundas transformações durante a ditadura, nas décadas de 1960 e 1970, um dos caminhos possíveis passa pela investigação dos processos históricos que nas décadas anteriores concorreram paras as mudanças ocorridas no espaço urbano e na sociedade brasileiros. Para analisar esse período que precede a golpes de Estado e ditaduras na América Latina, José Luis Romero mobiliza a tipologia da cidade massifica. Segundo Romero (2004, p. 353), "a crise de 1930 unificou visivelmente o destino latino-americano". Nesse momento, parecia haver "maior quantidade de gente que se movimentava mais, que gritava mais, que tinha mais iniciativa", enfim, "mais gente que largava a passividade e demonstrava estar disposta a participar da maneira que fosse da vida coletiva" (ROMERO, 2004, p. 353). Os dados estatísticos efetivamente mostram um maior crescimento populacional, representando no plano político e social uma nova força crescente na sociedade. Nas palavras de Romero (2004, p. 353), "começou a brotar por entre as brechas da sociedade organizada pessoas de origem indefinida que procuravam instalar-se nela". Esse foi o marco, dentro da tipologia proposta por Romero, no qual as cidades começaram a se massificar.

$\mathrm{Na}$ sociedade latino-americana, essa massificação ganhou força a partir de 1930, embora em regiões como a Europa esse seja um processo que remonta ao século XIX. Charles Dickens e Friedrich Engels mostraram, na primeira metade do século XIX, a situação dos trabalhadores nas grandes cidades inglesas, massificadas depois da revolução industrial, principalmente nos casos de Londres e de Manchester. Na Alemanha, no começo do século XX, Georg Simmel descreve algumas das características das grandes cidades europeias. Para Simmel (2005, p. 585), "o círculo URBANA, V.6, no 8, jun.2014 - Dossiê: Cidade e Habitação na América Latina - CIEC/UNICAMP 
de visão, as relações econômicas, pessoais e espirituais da cidade, os seus arredores ideais, assim que ultrapassam um determinado limiar, ampliam-se como em progressão geométrica". Por outro lado, Simmel (2005, p. 585) enfatizava que

não é apenas a grandeza imediata do distrito e o número de pessoas que, em virtude da correlação histórico-universal entre a ampliação do circuito e a liberdade pessoal, interior e exterior, tornam a cidade grande o local dessa última, mas sim o fato - ultrapassando essa amplitude de visão - de que as cidades grandes são também os locais do cosmopolitismo (Simmel, 2005, p. 585).

Em suas análises, José Luis Romero (2004, p. 355) aponta, como consequência do que chama "crise de 1930", uma "explosão urbana que transformaria as perspectivas da América Latina". Por um lado, nesse processo, muitas cidades não alteraram o seu ritmo de crescimento e, segundo o autor, permaneceram estagnadas. Por outro lado, viu-se a "decolagem de um determinado número de cidades, algumas das quais alcançaram com rapidez a categoria de metrópoles", transformando-se "em polos com tamanha importância em sua região e em seu país que influenciaram de modo decisivo a conjunto" (ROMERO, 2004, p. 355). Nesse processo, "imprecisos grupos sociais, alheios à estrutura tradicional, começaram a organizar-se, e receberam o nome de massas" (ROMERO, 2004, p. 355). O conjunto da sociedade urbana começou a se massificar, fazendo com que algumas cidades passassem por um rápido e intenso crescimento, sendo elementos desse processo a industrialização de algumas regiões e a imigração do campo para a cidade.

explosão demográfica e êxodo rural combinaram-se para configurar um fenômeno complexo e incisivo, no qual o quantitativo e o qualitativo se misturavam diabolicamente e cujo cenário seriam as cidades escolhidas para a concentração desses imigrantes desesperados e esperançosos ao mesmo tempo (Romero, 2004, p. 357).

Essa "massa" em movimento, que entrava em cena depois da "crise de 1930", fez com que emergissem grandes cidades, que viriam a se constituir, ao longo do século, em centros urbanos de importância econômica e política.

apenas cerca de dez cidades superavam, no ano de 1900 , os 100.000 habitantes. No entanto, em 1940, quatro cidades - Buenos Aires, México, Rio de Janeiro e São Paulo - ultrapassavam um milhão de habitantes, chegando a primeira a alcançar os dois milhões e meio. (...) No decorrer dos trinta anos seguintes a situação intensificou-se. Oito capitais não só ultrapassaram um milhão de habitantes como também, espalhando-se sobre extensas áreas metropolitanas, alcançaram cifras comparáveis às das cidades mais povoadas 
do mundo: duas delas, México e Buenos Aires, ultrapassaram os oito milhões e meio de habitantes (Romero, 2004, p. 361-2).

Essa "explosão urbana", nos termos de Romero (2004, p. 363), modificou o perfil das cidades, fazendo com que se queixassem desse crescimento "aqueles que desfrutaram dela antes, aprazíveis e tranquilos, mas, sobretudo, com uma infraestrutura suficiente para o número de habitantes que possuíam". Como consequência do crescimento, "os serviços públicos se tornavam cada vez mais deficientes, as distâncias mais longas, o ar mais impuro, os ruídos mais ensurdecedores" (ROMERO, 2004, p. 364). Por outro lado, as massas adquiriram cada vez mais influência nessas cidades.

as tensões intensificaram-se porque o crescimento desmedido da população urbana criou um círculo vicioso: quanto mais a cidade crescia, mais expectativas criava e, em consequência, atraía mais gente, porque parecia poder absorvê-la; mas, a rigor, o número dos que se incorporavam à estrutura urbana era sempre superior ao que a estrutura podia suportar (Romero, 2004, p. 361).

No entanto, segundo Romero (2004, p. 375), no transcorrer das décadas seguintes a "nova massa urbana" perdeu a agressividade, na medida em que "o processo de industrialização acentuou-se e com ele multiplicaram-se as possibilidades ocupacionais" e, com isso, "se não todos, por certo muitos dos membros daquela massa instável e desorientada foram encontrando os caminhos para alcançar ou fortalecer a sua inserção social". Nesse processo, as pequenas classes médias e as classes populares "ficaram deslocadas após as primeiras experiências de sua massificação", deixando "a dúvida se o indivíduo economicamente enfraquecido podia melhorar sua condição por seu próprio esforço, como garantia a ideologia da ascensão social, ou se tinha de apelar para a pressão coletiva" (ROMERO, 2004, p. 375). Por outro lado, produziu-se a exigência de "que a mudança fosse realizada dentro das linhas fundamentais de desenvolvimento da estrutura", por meio de uma nova ideologia, conhecida como populismo (ROMERO, 2004, p. 413). Essas mudanças deveriam ser conduzidas pelas mãos de seus defensores, que compunham a estrutura do Estado. Essa nova ideologia deveria promover "a aceleração da moderada mudança" almejada pela "nova massa urbana e que, a princípio, só pareciam querer ajuda para alcançar o nível da subsistência e da segurança, quais que fossem as condições a Ihe serem impostas" (ROMERO, 2004, p. 414). Como parte da busca de um consenso nessa sociedade, 
um paternalismo decidido, sincero, espontâneo e sentimental em alguns, calculado e astuto em outros, foi acolhido como o único caminho eficaz para acelerar o processo de incorporação dos marginalizados à estrutura. A figura dos protetores se agigantou aos olhos dos indefesos, e a esperança em Deus e talvez em um ocasional e carismático caudilho que parecia encarnar sua misericórdia seduziu aqueles que, imersos já irremediavelmente no mundo industrial, ignoravam os diabólicos segredos que se ocultavam no revés de sua trama (ROMERO, 2004, p. 415-6).

Contudo, foi temporária essa aparente estabilidade social e política, pois "as necessidades da massa urbana eram cada vez mais urgentes e maiores", podendo ameaçar a estabilidade, provocando reações inclusive agressivas, e "também porque podiam estimular desvios para tendências e doutrinas revolucionárias" (ROMERO, 2004, p. 417). Em função disso, difundiu-se a ideia de que "a sociedade estava obrigada a socorrer as necessidades primárias daqueles que careciam de recursos e protegê-los contra a exploração do sistema que os tornava vítimas" (ROMERO, 2004, p. 418). Essa ideologia de bem-estar social recebeu grande apoio das "massas". Segundo Romero (2004, p. 418), "multidões inflamadas exteriorizavam o seu apoio nas praças públicas de muitas cidades, e em quase todas houve vastos grupos que se surpreenderam vendo-se acalentar uma esperança".

Contudo, essa adesão da "massa" em apoio à estrutura estatal estabelecida "não era passiva nem estável, talvez como resultado da intensa polarização que foi tomando conta das cidades" (ROMERO, 2004, p. 420). Essa adesão das "massas" era "condicionada, e seus termos foram mudando não só ao compasso das situações de fato", mas "também ao de certo esclarecimento obtido na comunicação com outros grupos urbanos de diferentes tendências políticas, em especial nas cidades que se industrializavam" (ROMERO, 2004, p. 420). Nessa "massa", contudo, "alguns começaram a pensar que, em compensação, era necessário chegar até as últimas consequências que comportava a ideologia da justiça social, ultrapassando os limites previstos pelo populismo" (ROMERO, 2004, p. 420). Essa irrupção de "massas" pode ser vista, entre outros, no Brasil, depois de 1961, percebendo-se nessa "flutuação dos grupos sociais e das posições ideológicas (...) a magnitude e a profundidade do impacto da massificação urbana" (ROMERO, 2004, p. 421).

Os setores mais conservadores viram na irrupção das "massas", antes mesmo de 1961, uma ameaça à estabilidade da estrutura engendrada nas décadas anteriores. Com isso, uma das interpretações possíveis para o golpe de 1964, no Brasil, passa por encará-lo como resposta conservadora à ameaça de vitória de um projeto de transformações profundas na sociedade que apontasse para a superação da "justiça 
social" proposta pelo populismo. Com o golpe, rompeu-se o consenso entre o Estado e as "massas", fechando canais de discussão e participação política da maior parte da população. Se antes o Estado utilizava-se da retórica da justiça e do bem estar social, respondendo com algumas ações paliativas as aspirações das "massas" por melhoria de vida, depois do golpe o Estado passou a impor sobre as massas as ações dos seus governantes, encontrando inclusive apoio nos setores médios da sociedade, em alguns contextos. Nas cidades, as multidões não poderiam se mover sem a permissão do Estado e sua vida e seu destino cada vez mais estavam marcados pelas decisões de técnicos e planejadores vinculados ao Estado.

\section{Construindo a cidade da ditadura}

Depois de 1964, com a ascensão da ditadura, intensificou-se a intervenção do Estado sobre a sociedade. No caso do espaço urbano, bem como em diferentes esferas da administração pública, aprofundou-se a intervenção autoritária por meio de um planejamento realizado por técnicos e burocratas. Benício Schmidt (1986, p. 33) aponta duas fases da intervenção sobre as cidades durante a ditadura. Primeiro, entre 1964 e 1972, as "demandas econômicas e sociais tinham que ser tratadas de maneira a acentuar a acumulação de capital em setores urbanos chave", liberando "o governo do encargo de fornecer subsídios" e priorizando a execução de uma política habitacional. Em um segundo momento, a partir de 1973, "foi decidido que as políticas estatais deveriam se sujeitar a critérios espaciais destinados a superar desequilíbrios regionais seculares", delimitando-se, a partir disso, "uma complexa política urbana, nacional e regional" (SCHMIDT, 1986, p. 33). Nesse segundo momento,

o desenvolvimento regular de uma política urbana concebida como "política habitacional" rumo à concepção mais complexa de "política espacial que se baseia nas áreas metropolitanas" implicou mudanças fundamentais na natureza do regime político e do Estado no Brasil, incluindo a intervenção econômica mais volumosa, a centralização crescente e uma percepção mais aguda de parte do Estado dos limites à acumulação de capital (SCHMIDT, 1986, p. 33).

O principal marco dessa nova política foi o II Plano Nacional de Desenvolvimento (II PND), principalmente no capítulo referente ao "Desenvolvimento urbano, controle da poluição e preservação do maio-ambiente", que tinha como objetivo a implantação de um "programa que visava promover as cidades de porte URBANA, V.6, no 8, jun.2014 - Dossiê: Cidade e Habitação na América Latina - CIEC/UNICAMP 
médio a centros estratégicos da rede urbana nacional" (STEINBERGER \& BRUNA, 2001 , p. 35). O plano tinha como proposta geral "favorecer a criação de polos secundários, as cidades de porte médio, que se aproveitariam das vantagens das aglomerações existentes", também servindo "de base a uma estruturação de apoio à formação de um sistema urbano nacional mais equilibrado" (STEINBERGER \& BRUNA, 2001, p. 46-7). O documento partia da seguinte caracterização:

É conhecido o desequilíbrio, que se tem agravado, no processo de urbanização do País. Observe-se, de um lado, um processo de metropolitanização prematura, com a proliferação de grandes aglomerados urbanos, que continuam crescendo a taxas aceleradas, e, de outro lado, a excessiva pulverização de pequenas cidades, sem um número adequado de cidades médias que dê razoável equilíbrio ao conjunto. (...) Em apenas 30 anos a população urbana do País quase duplicou sua participação relativa, evoluindo dos $31 \%$ em 1940, para os $56 \%$ em 1970 . Esse processo de urbanização decorreu, em grande parte, das migrações internas do campo para as cidades, e significou uma expansão da população urbana equivalente a 40 milhões de pessoas (BRASIL, 1974, p. 77).

Como consequência da urbanização acelerada e das distorções por ela provocadas na distribuição espacial das cidades, localizadas principalmente no litoral, "os principais aglomerados metropolitanos localizam-se na costa atlântica, concentrando $2 / 5$ da população das cidades, a maior parte das atividades industriais e a maior responsabilidade no que tange à expansão da economia" (BRASIL, 1974, p. 78). Por outro lado, segundo o documento, a concentração urbana, que ocorre principalmente "nas regiões metropolitanas de São Paulo e Rio de Janeiro, está acarretando sérios problemas de congestionamento, superpopulação e poluição, em detrimento da qualidade de vida e do equilíbrio social" (BRASIL, 1974, p. 78).

Como forma de solucionar esses problemas, o documento propunha "identificar as funções que devem ser cumpridas pelas metrópoles nacionais e as que devem ser desempenhadas pelas metrópoles regionais, notadamente nas áreas de maior concentração populacional e econômica" (BRASIL, 1974, p. 79). A partir disso, seria possível "definir polos secundários imprescindíveis a uma política de descentralização, de âmbito nacional ou regional, com adequado aproveitamento das vantagens de aglomeração existentes", estabelecendo nas novas regiões "núcleos urbanos de apoio ao processo de ocupação" (BRASIL, 1974, p. 79). Por outro lado, o documento também propunha "identificar as funções que devem ser cumpridas pelas metrópoles nacionais e as que devem ser desempenhadas pelas metrópoles regionais, 
notadamente nas áreas de maior concentração populacional e econômica" (BRASIL, 1974, p. 79).

Percebe-se nesse programa uma estratégia geral para o território do país, baseada na desconcentração e na interiorização (STEINBERGER \& BRUNA, 2001, p. 44). Se a solução para as metrópoles da região sudeste seria "evitar o crescimento excessivo das grandes aglomerações urbanas", o caminho para outras regiões deveria ser diferente, como a nordeste, onde se pretendia "a dinamização da base econômica das metrópoles regionais do sistema urbano", além do "reforço das atividades produtivas e dos equipamentos dos polos urbanos" (BRASIL, 1974, p. 79). Para as regiões norte e centro-oeste, se pretendia "a promoção da urbanização nas áreas de ocupação recente ou não consolidas", bem como "a organização do desenvolvimento das metrópoles regionais em formação e da região geoeconômica de Brasília" (BRASIL, 1974, p. 79). Para a região sul, que ainda não padecia dos problemas da região sudeste, mas que não era uma região pouco habitada como o norte ou o centro-oeste, se pretendia o crescimento "ordenado das metrópoles regionais e o fortalecimento dos núcleos urbanos de médio porte" (BRASIL, 1974, p. 79).

Esses problemas e propostas para solução foram detalhados pelo Programa para Cidades de Porte Médio, do governo federal, de 1976. Esse programa visava "proporcionar uma descentralização econômica nas cidades-polo de desenvolvimento do interior", "evitar um acúmulo de problemas nas regiões metropolitanas" e reforçar pontos que possam "direcionar o processo de urbanização de maneira mais racional e estruturante, gerando opções aos fluxos migratórios e de capital" (PROGRAMA, 1976, p. 20). Por fim, o programa também pretendia "estender sua atuação tanto em áreas urbanas hipertrofiadas, como naquelas cujo processo de urbanização esteja por ficar saturado" (PROGRAMA, 1976, p. 20). O programa apontava, portanto, conforme apontado no II PND, para o controle do crescimento nas grandes metrópoles e uma interiorização do desenvolvimento, seja fortalecendo polos regionais do sul e do nordeste, seja promovendo a ocupação de alguns territórios no norte e no nordeste. Como estratégia, seria preciso

identificar cidades de porte médio em condições de atuar como suporte às atividades econômicas do seu entorno, maximizando-se as funções urbanas que possuem - além de diminuir seu grande grau de dependência em relação a centros mais dinâmicos - ampliar a sua área de influência onde cidades de menor porte obtenham reflexos dos efeitos multiplicadores e estruturantes a nivelo microrregional (PROGRAMA, 1976, p. 20). 
O principal fundamento dessa política da ditadura passava pela integração nacional, elemento doutrinário que balizava a doutrina da Escola Superior de Guerra (ESG) e que estava presente na elaboração do II PND, bem como de outros documentos governamentais. No caso das cidades, pensava-se na possibilidade de equilibrar os polos urbanos, mantendo as grandes metrópoles e, junto disso, fortalecendo núcleos urbanos de porte médio. Esses núcleos urbanos, ainda que não tomassem o lugar político e econômico das grandes cidades, poderiam se constituir em polos de atração para as migrações, evitando assim que essas onde migratórias se dirigissem às grandes metrópoles, como Rio de Janeiro e São Paulo. Por outro lado, segundo os gestores da ditadura, essa política poderia desenvolver economicamente a região, atraindo empresas ou ramos econômicos.

Contudo, ainda que se tenham construído estradas e melhorado os sistemas de telecomunicações, o principal balanço negativo desse projeto para as cidades de porte médio passa justamente pela fragilidade da integração nacional. Pode-se afirmar que "os benefícios foram somente pontuais, ou seja, em cada uma das cidades envolvidas, frustrando qualquer tipo de expectativa de uma atuação interurbana que promoveria as cidades médias a centros estratégicos da rede urbana nacional" (STEINBERGER \& BRUNA, 2001, p. 62). Assim, a política da ditadura para as cidades de porte médio, ainda que a estratégia fosse outra, "consistiu em uma experiência espacialmente fragmentada" (STEINBERGER \& BRUNA, 2001, p. 63).

Embora o projeto de integração nacional tenha se mostrado bastante frágil em seus resultados, o Programa para as cidades de porte médio conseguiu cumprir algumas de suas metas. Primeiro, em alguns casos, consolidou a liderança regional de algumas cidades, como aquelas localizadas na região oeste de seus estados, como Cascavel e Chapecó, respectivamente no Parará e em Santa Catarina. Embora não se tenham integrado à nação como esperava a ditadura, afinal permaneciam afastadas até mesmo de suas capitais, essas e outras cidades conseguiram se consolidar como polos regionais de influência econômica e política e, em alguns casos, constituíram colaborações regionais. Os investimentos em obras e infraestrutura, a partir da verba oriunda do Programa, transformaram profundamente essas cidades, num sentido de remodelação e de reorganização do espaço urbano, com vistas a certo projeto de modernização que passava pela manutenção da ordem política e pela realização de certo progresso econômico e social. Por outro lado, as multidões, que se aglomeravam de forma desordenada, precisariam ser excluídas ou pelo menos afastadas dessa cidade moderna que se pretendia construir, na medida em que se tornavam atores 
políticos relevantes, como se percebe em mobilizações populares ocorridas no final da ditadura, principalmente a partir de 1979.

\section{Considerações finais}

Conforme se procurou discutir neste artigo, as cidades latino-americanas, de forma geral, e as brasileiras, em particular, passaram por um processo de massificação a partir de aproximadamente de 1930. Trata-se de um processo em que, paralelamente à industrialização e à urbanização, multidões entram para o cenário social e político das cidades, construindo esses espaços em seu cotidiano ou reivindicando mudanças e condições melhores de vida. Emergem, assim, grandes metrópoles, que reúnem milhares ou mesmo milhões de pessoas, transformando intensamente o espaço urbano e cada vez mais necessitando de necessidades elementares para sua sobrevivência, como saúde e emprego, e equipamentos urbanos que permitem melhores condições de vida. Em muitos casos, não se realizou o mundo prometido que levou migrantes às grandes cidades, colocando as multidões em cena não como massa disforme e descaracterizada, mas como força política em busca de direitos sociais, reivindicando transformações reais e não apenas reformas, e, com isso, provocando a reação das forças conservadoras.

Com a emergência da ditadura, fecha-se esse ciclo de consciência, organização e ação política das multidões, principalmente pela força da repressão policial. No caso das cidades, passa-se a um processo de investimento na transformação do espaço, seja como forma de controlar as "massas", seja para fazer circular o capital. Nos primeiros anos da ditadura apostou-se em um conjunto de políticas habitacionais, associadas à expansão de alguns direitos sociais, mostrando a aposta dos gestores na concessão de reivindicações das mais básicas e que evitassem mobilizações sociais e ações políticas coletivas.

Contudo, essa mesma ditadura, na década de 1970, apostou na transformação do espaço urbano da cidade por meio da intervenção estatal, muitas vezes com características autoritárias, recriando esses espaços sem a efetiva participação dos atores que produzem essa cidade. Ainda assim, embora o Estado atuasse de forma autoritária, não poderia por decreto recriar a cultura e as formas que tem a população de praticar a cidade. 


\section{Referências}

BRASIL. Projeto do II Plano Nacional de Desenvolvimento - PND (1975-1979). Brasília: s.n., 1974.

GORELIK, Adrián. A produção da "cidade latino-americana". Tempo Social, São Paulo, v. 17, no 1, p. 111-133, jun. 2005.

LEPETIT, Bernard. Por uma nova história urbana. São Paulo: USP, 2001. PROGRAMA para cidades de porte médio. Planejamento \& Desenvolvimento, Brasília, Secretaria de Desenvolvimento da Presidência da República, ano 3, no 36, p. 20-5, maio 1976.

ROMERO, José Luis. América Latina: as cidades e as ideias. Rio de Janeiro: UFRJ, 2004.

SCHMIDT, Benicio Viero. A questão urbana. Rio de Janeiro: Zahar, 1986.

SIMMEL, Georg. As grandes cidades e a vida do espírito. Mana, v. 11, n. 2, 2005.

STEINBERGER, Marília; BRUNA, Gilda Collet. Cidades médias: elos do urbano-regional e do público-privado. In: ANDRADE, Thompson; SERRA, Rodrigo (Org.). Cidades médias brasileiras. Rio de Janeiro: IPEA, 2001, p. 35-77. 